\title{
DESEMPENHO DE REATORES ANAERÓBIOS DE FLUXO ASCENDENTE COM MANTA DE LODO EM DOIS ESTÁGIOS TRATANDO ÁGUAS RESIDUÁRIAS DE SUINOCULTURA
}

\author{
ADRIANA M. DE SANTANA ${ }^{1}$, ROBERTO A. DE OLIVEIRA ${ }^{2}$
}

RESUMO: Avaliou-se o desempenho de dois reatores anaeróbios de fluxo ascendente com manta de lodo (UASB) em escala-piloto com volumes de 908 L e 188 L, instalados em série, alimentados com águas residuárias de suinocultura com concentrações médias de sólidos suspensos totais (SST) variando de $2.216 \mathrm{mg} \mathrm{L}^{-1}$ a $7.131 \mathrm{mg} \mathrm{L}^{-1}$ e submetidos a tempos de detenção hidráulica (TDH) de 62,3 e 31,1 h, no primeiro reator, e de 12,9 e 6,5 h, no segundo reator. As eficiências médias de remoção de $\mathrm{DQO}_{\text {total }}$ variaram de $74,0 \%$ a $89,6 \%$ no Reator 1 e de $34,3 \%$ a $45,1 \%$ no Reator 2, resultando em valores médios de $86,6 \%$ a $93,1 \%$ para o sistema de tratamento em dois estágios com carga orgânica volumétrica $(\mathrm{COV})$ na faixa de 3,40 a $14,44 \mathrm{~kg} \mathrm{DQO}_{\text {total }} \mathrm{m}^{-3}$ reator d $\mathrm{d}^{-1}$ no Reator 1 . As concentrações de metano no biogás foram acima de $75 \%$ para o Reator 1 e de $80 \%$ para o Reator 2 . Os valores médios de pH variaram na faixa de 6,9 a 8,2 para o efluente do Reator 1 e de 7,0 a 8,3 para o efluente do Reator 2. Os ácidos voláteis totais mantiveram-se estáveis com concentrações médias abaixo de $200 \mathrm{mg} \mathrm{L}^{-1}$. Esses resultados indicaram que as condições de carga orgânica, em termos de DQO e SSV, impostas ao sistema de tratamento anaeróbio em dois estágios, não foram limitantes para que houvesse o desenvolvimento de lodo com microbiota adaptada e com alta atividade, propiciando altas eficiências médias de remoção de matéria orgânica (86,6 a 93,1\% para $\mathrm{DQO}_{\text {total }}$ e 85,6 a 88,2\% para SSV) e taxas de produção de metano de 0,156 a $0,289 \mathrm{~m}^{3} \mathrm{CH}_{4} \mathrm{~kg}^{-1}$ de DQO removida.

PALAVRAS-CHAVE: digestão anaeróbia, reator UASB, resíduo de suínos.

\section{PERFORMANCE OF TWO-STAGE UP FLOW ANAEROBIC SLUDGE BLANKET REACTORS TREATING SWINE WASTEWATER}

\begin{abstract}
The objective of this work was monitoring the performance of two up flow anaerobic sludge blanket reactors (UASB) in a pilot-scale testing with volumes of $908 \mathrm{~L}$ and $188 \mathrm{~L}$, installed in series, loaded with swine wastewater with total suspended solids (TSS) ranging from 2216 to $7131 \mathrm{mg} \mathrm{L}^{-1}$, submitted to an hydraulic detention time (HDT) of 62.3 and $31.1 \mathrm{~h}$, in the first reactor, and 12.9 and $6.5 \mathrm{~h}$, in the second reactor. The mean total COD removal efficiency varied from 74.0 to $89.6 \%$ in reactor 1 , and from 34.3 to $45.1 \%$ in reactor 2 , resulting average values ranging from 86.6 to $93.1 \%$ for the two-stage treatment system under organic volumetric load (OVL) of 3.40 to $14.44 \mathrm{~kg}$ $\mathrm{COD}_{\text {total }} \mathrm{m}^{-3}$ reactor $\mathrm{d}^{-1}$ in the reactor 1 . The methane concentration in biogas values was over $75 \%$ in reactor 1 and $80 \%$ in reactor 2 . Average $\mathrm{pH}$ values in the effluents ranged from 6.9 to 8.2 in reactor 1 and 7.0 to 8.3 for reactor 2 . The amount of total volatile acids remained steady showing mean concentrations bellow $200 \mathrm{mg} \mathrm{L}^{-1}$. According to these results the organic loading conditions, concerning to the COD and VSS imposed to the two-stage anaerobic treatment system were not limiting to the sludge blanket development of extremely active and adapted micro biota providing high mean values of organic matter removal, from 86.6 to $93.1 \%$ to the $\mathrm{COD}_{\text {total }}$ and 85.6 to $88.2 \%$ to VSS, and the rate of volumetric methane production from 0.156 to $0.289 \mathrm{~m}^{3} \mathrm{CH}_{4} \mathrm{~kg}^{-1} \mathrm{COD}$ removed.
\end{abstract}

KEYWORDS: anaerobic digestion, UASB reactor, swine waste.

\footnotetext{
${ }^{1}$ Bióloga, Mestre em Microbiologia Agropecuária, UNESP - Jaboticabal, adrims@ fcav.unesp.br. Bolsista FAPESP

${ }^{2}$ Eng $^{\mathrm{o}}$ Agr $^{\mathrm{o}}$ e Tecnólogo em Construção Civil, Doutor em Hidráulica e Saneamento, Departamento de Engenharia Rural, UNESP Jaboticabal, oliveira@fcav.unesp.br

Recebido pelo Conselho Editorial em: 4-6-2004

Aprovado pelo Conselho Editorial em: 16-11-2005
} 


\section{INTRODUÇÃO}

Dentre os progressos científicos e tecnológicos que mais contribuíram para o desenvolvimento do tratamento anaeróbio de águas residuárias, destaca-se a notável evolução do conhecimento dos processos microbiológicos, interagindo com os avanços obtidos pelas várias configurações de reatores estudadas.

O bom desempenho dos reatores anaeróbios modernos, denominados avançados ou nãoconvencionais, é conseqüência da organização dos microrganismos anaeróbios e sua retenção no reator. Os microrganismos fisicamente organizados no lodo em aglomerados bacterianos, em grânulos biológicos, ou em biofilme ficam retidos dentro do sistema (VAZOLLER, 2002).

Os reatores anaeróbios de fluxo ascendente com manta de lodo (UASB) apresentam características hidrodinâmicas favoráveis à formação de grânulos, possibilitando elevado tempo de retenção celular e acomodando, portanto, altas cargas orgânicas volumétricas, com tempo de detenção hidráulica curto, da ordem de grandeza de horas, dependendo das condições operacionais e das características dos afluentes, sendo possível desvincular o tempo de retenção celular do tempo de detenção hidráulica (FORESTI, 1994).

As águas residuárias de suinocultura apresentam altas concentrações de sólidos suspensos orgânicos, provocando impactos ambientais acentuados em várias regiões do Brasil, bem como em outros países. A suinocultura no Brasil vem destacando-se no cenário do comércio internacional pela sua elevada qualidade técnica e produtividade. $\mathrm{O}$ rebanho nacional de aproximadamente 35 milhões de suínos tem elevada densidade demográfica no Rio Grande do Sul, Santa Catarina e Paraná, com acelerado desenvolvimento em São Paulo, Goiás, Mato Grosso do Sul, Mato Grosso e Minas Gerais. Com o crescimento da produtividade, cresceram também os problemas decorrentes da disposição dos dejetos, estimando-se uma produção de 32 a 51 milhões de toneladas por ano, os quais apresentam altas concentrações de matéria orgânica (ISHIZUKA, 2003).

A inadequação dos sistemas de manejo e armazenamento induz o lançamento de grandes quantidades de dejetos no solo ou em corpos d'água, podendo ocasionar sérios problemas de poluição (OLIVEIRA, 1997).

Os reatores UASB, assim como outros reatores anaeróbios de alta taxa, apresentam limitações para o tratamento de águas residuárias com altas concentrações de sólidos suspensos. LETTINGA et al. (1980) estabeleceram valores abaixo de $1.000 \mathrm{mg} \mathrm{L}^{-1} \mathrm{e}$, posteriormente, ampliaram para $6.000 \mathrm{a}$ $8.000 \mathrm{mg} \mathrm{L}^{-1}$ (LETTINGA \& HULSHOFF-POL, 1991), contudo poucos estudos foram realizados confirmando essa última recomendação.

As principais limitações dos reatores anaeróbios para o tratamento de afluentes com altas concentrações de sólidos suspensos estão relacionadas à hidrólise dos sólidos orgânicos. A utilização do processo anaeróbio em dois estágios com reatores UASB pode propiciar melhor desempenho na remoção de sólidos suspensos orgânicos, incrementando a hidrólise no primeiro reator, e conferir maior estabilidade ao sistema de tratamento, alcançando altas eficiências de remoção de matéria orgânica e de produção de metano (OLIVEIRA, 2001 e 2003; LIER et al., 2001, e PEREIRA, 2003).

Considerando essas possibilidades, neste trabalho, avaliou-se o desempenho de reatores UASB em dois estágios, tratando águas residuárias de suinocultura com concentrações de sólidos suspensos totais crescentes de $2.216 \mathrm{mg} \mathrm{L}^{-1}$ a $7.131 \mathrm{mg} \mathrm{L}^{-1}$, variando o tempo de detenção hidráulica de $62,3 \mathrm{~h} \mathrm{e}$ $31,1 \mathrm{~h}$ no primeiro reator e 12,9 e $6,5 \mathrm{~h}$ no segundo reator. 


\section{MATERIAL E MÉTODOS}

$\mathrm{O}$ experimento foi realizado na área de Digestão Anaeróbia do Departamento de Engenharia Rural da Faculdade de Ciências Agrárias e Veterinárias da Universidade Estadual Paulista - UNESP, Câmpus de Jaboticabal. O sistema de tratamento anaeróbio, em dois estágios, foi constituído por dois reatores UASB em escala-piloto, instalados em série, com volumes de $908 \mathrm{~L}$ (primeiro estágio) e 188 L (segundo estágio). Também foram montadas caixas para preparação (peneiramento e diluição) dos dejetos de suínos, caixas para armazenamento do afluente com agitação e bomba helicoidal para alimentação dos reatores UASB, conforme ilustrado na Figura 1. Para o monitoramento da produção de biogás, foram instalados dois selos hidráulicos e gasômetros, conforme descrito por OLIVEIRA (1997 e 2001).

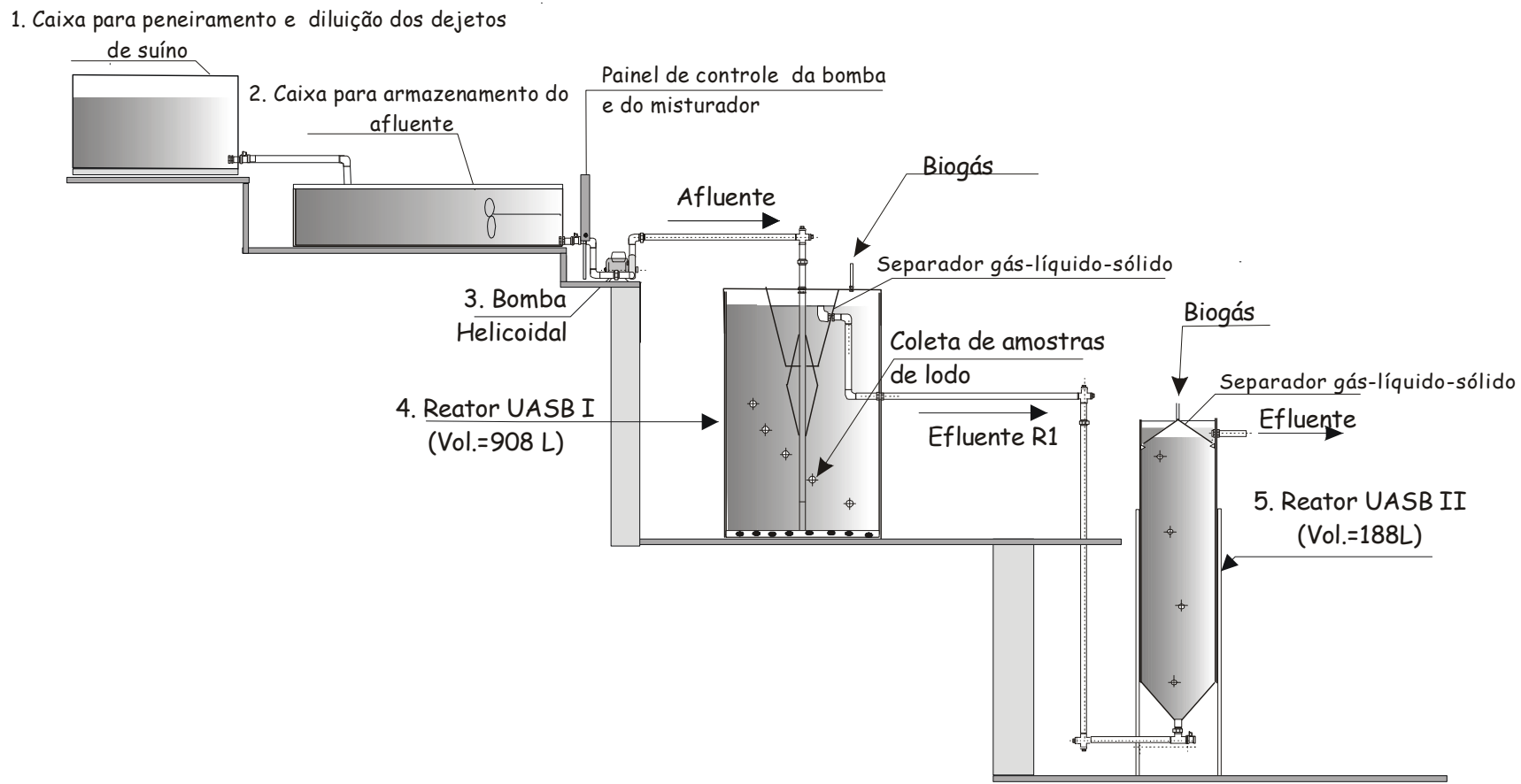

FIGURA 1. Corte longitudinal esquemático do sistema de tratamento anaeróbio em dois estágios, em escala-piloto, com reator UASB de $908 \mathrm{~L}$, construído em argamassa armada (4), e reator UASB de 188 L, construído com tubo de PVC (5).

O substrato utilizado para a alimentação contínua dos reatores UASB foi o esterco de suínos diluído e pré-peneirado para obtenção de concentrações de sólidos suspensos totais (SST) desejadas, em torno de 2,0 $\mathrm{g} \mathrm{L}^{-1}$ a 7,0 $\mathrm{g} \mathrm{L}^{-1}$, para as fases I e II, respectivamente, no afluente do Reator 1 . O esterco bruto utilizado para preparar o resíduo diluído foi coletado em confinamento de suínos em fase de terminação, alimentados com ração à base de milho ou sorgo e soja, com complemento vitamínico e mineral.

O experimento foi dividido em quatro ensaios, variando-se o tempo de detenção hidráulica (TDH) nos reatores e as concentrações de SST no afluente do primeiro reator (Tabela 1).

Para a partida dos reatores UASB, foi utilizado como inóculo lodo proveniente de reatores UASB tratando águas residuárias de suinocultura com concentrações de SST de $2.000 \mathrm{mg} \mathrm{L}^{-1} \mathrm{e}$ $\mathrm{DQO}_{\text {total }}$ de $4.000 \mathrm{mg} \mathrm{L}^{-1}$. O volume de lodo colocado nos reatores foi em torno de 30 a $40 \%$ do volume de cada reator. 
TABELA 1. Condições de operação do Reator 1 (R1) e Reator 2 (R2), nos ensaios 1; 2; 3 e 4 do sistema de tratamento anaeróbio, em dois estágios

\begin{tabular}{|c|c|c|c|c|c|c|}
\hline \multirow[t]{2}{*}{ Fases } & \multirow[t]{2}{*}{ Ensaio } & \multirow{2}{*}{$\begin{array}{c}\text { Duração } \\
\text { (dias) }\end{array}$} & $\begin{array}{c}\mathrm{TDH}^{(\mathrm{a})} \\
\text { (h) }\end{array}$ & \multirow{2}{*}{$\begin{array}{c}\mathrm{SST}^{(\mathrm{b})} \\
\text { Afluente }\left(\mathrm{mg} \mathrm{L}^{-1}\right) \\
\mathrm{R} 1 \\
\end{array}$} & \multirow{2}{*}{$\begin{array}{c}\text { DQO }_{\text {total }}{ }^{(\mathrm{c})} \\
\text { Afluente }\left(\mathrm{mg} \mathrm{L}^{-1}\right) \\
\mathrm{R} 1\end{array}$} & \multirow{2}{*}{$\begin{array}{c}\mathrm{COV}^{(\mathrm{d})} \\
\left(\mathrm{kg} \mathrm{DQO}_{\text {total }} \mathrm{m}^{-3} \text { reator }^{-1}\right) \\
\mathrm{R} 1\end{array}$} \\
\hline & & & R1 R2 & & & \\
\hline \multirow{2}{*}{ I } & 1 & 45 & $\begin{array}{ll}62,3 & 12,9\end{array}$ & 2.216 & 8.818 & 3,40 \\
\hline & 2 & 45 & $31,1 \quad 6,5$ & 2.803 & 9.625 & 7,43 \\
\hline \multirow{2}{*}{ II } & 3 & 46 & $62,3 \quad 12,9$ & 4.300 & 13.844 & 5,33 \\
\hline & 4 & 50 & $31,1 \quad 6,5$ & 7.131 & 18.717 & 14,44 \\
\hline
\end{tabular}

(a) - tempo de detenção hidráulica; (b) - sólidos suspensos totais; (c) - demanda química de oxigênio; (d) - carga orgânica volumétrica.

As amostras dos afluentes e efluentes foram coletadas nas torneiras de amostragem na alimentação e nas saídas do Reator 1 e Reator 2. Para os exames e determinações de DQO total, $_{\text {, }}$ DQO $_{\text {dissolvida, }}$ DQO ss, $_{\text {s }}$ ST e SSV, foram utilizadas amostras compostas com subamostras de $50 \mathrm{~mL}$, coletadas a cada 1 hora, no período de 7 h30 às 13h30, duas vezes por semana, sendo realizadas de acordo com APHA, AWWA, WPCF (1992) e OLIVEIRA (1997). O volume do biogás produzido foi monitorado diariamente, por meio de medidas em gasômetros metálicos, como descrito por OLIVEIRA (1997), e a composição do biogás foi analisada semanalmente, em cromatografia gasosa, conforme descrito por APHA, AWWA, WPCF (1992).

As medidas de alcalinidade total (AT) e pH foram efetuadas diariamente, segundo metodologia descrita por APHA, AWWA, WPCF (1992), e os ácidos voláteis totais (AVT) foram analisados duas vezes por semana, conforme descrito por DILALLO \& ALBERTSON (1961).

\section{RESULTADOS E DISCUSSÃO}

Na Tabela 2, estão apresentados os valores médios das cargas orgânicas volumétricas (COV), em termos de $\mathrm{DQO}_{\text {total, }}$ e características dos afluentes e dos efluentes dos Reatores 1 e 2, obtidos durante os ensaios. Na Tabela 3, estão apresentados os valores médios de desempenho nos quatro ensaios do experimento com os Reatores em dois estágios. A variação nas eficiências de remoção de $\mathrm{DQO}_{\text {total }} \mathrm{e}$ SST nos Reatores 1 e 2 está apresentada nas Figuras 2 e 3.

Os valores médios de SST e SSV do afluente do Reator 1 foram crescentes (Tabela 2), respectivamente, para os ensaios 1 a 4 . Nos ensaios 1 e 2, fase I do experimento, as concentrações médias de SST foram de 2.216 e $2.803 \mathrm{mg} \mathrm{L}^{-1}$, respectivamente. Nos ensaios 3 e 4 , fase II do experimento, os valores médios aumentaram para 4.300 e $7.131 \mathrm{mg} \mathrm{L}^{-1}$, respectivamente.

KALYUZHNYI et al. (2000) citaram concentrações de sólidos totais (ST), nas águas residuárias de suinocultura, de 0,5 a 4,0\%. SOUZA (2001) realizou levantamento das características das águas residuárias de suinocultura de várias granjas e encontrou valores de ST de 24.133 a $85.264 \mathrm{mg} \mathrm{L}^{-1}$ e DQO de 61.972 a $94.000 \mathrm{mg} \mathrm{L}^{-1}$. OLIVEIRA et al. (2000) citaram concentrações de ST de $2.400 \mathrm{mg}$ $\mathrm{L}^{-1}$ em águas residuárias de suinocultura. OLIVEIRA et al. (1995) observaram que as concentrações de ST e SST de 26.885 e $14.610 \mathrm{mg} \mathrm{L}^{-1}$, respectivamente, das águas residuárias de suinocultura, diminuíram para 13.400 e $1.640 \mathrm{mg} \mathrm{L}^{-1}$, após a passagem por uma peneira vibratória, e para 6.770 e $1.430 \mathrm{mg} \mathrm{L}^{-1}$, após o sedimentador instalado em série.

Neste trabalho, foram utilizadas concentrações médias de SST do afluente de 2.216 a $7.131 \mathrm{mg} \mathrm{L}^{-1}$, considerando-se instalações de criação de suínos em confinamento com uso intensivo de água para a higienização e/ou com a separação mecânica preliminar das frações sólidas e líquidas das águas residuárias de suinocultura. 
Os valores médios da $\mathrm{DQO}_{\text {total }}$ do afluente do Reator 1 variaram de 8.818 a $18.717 \mathrm{mg} \mathrm{L}^{-1}$, para a DQO $_{\text {dissolvida }}$ de 2.073 a $5.429 \mathrm{mg} \mathrm{L}^{-1}$ e para a $\mathrm{DQO}_{\mathrm{ss}}$ de 5.519 a $13.288 \mathrm{mg} \mathrm{L}^{-1}$. Nas águas residuárias de suinocultura utilizadas, observaram-se valores médios da relação $\mathrm{DQO}_{\text {total }} / \mathrm{SST}$ variando de 2,6 a 4,0 e de $\mathrm{DQO}_{\mathrm{ss}} / \mathrm{DQO}_{\text {total }}$ de 0,57 a 0,77, indicando a predominância de sólidos suspensos orgânicos, conforme também foi observado por LO et al. (1994), SANCHEZ et al. (1995), KALYUZHNYI et al. (1999), KALYUZHNYI \& SKLYAR (2000), OLIVEIRA (1997, 2001 e 2003) e PEREIRA (2003).

Houve variações mais acentuadas na $\mathrm{DQO}_{\text {total }}$ e SST do afluente do Reator 1 nos ensaios 1 e 4. Apesar dessas variações, observaram-se concentrações estáveis de DQO $_{\text {total }}$ e SST para cada ensaio nos efluentes dos Reatores 1 e 2, propiciando os altos valores de eficiência de remoção de DQO total $_{\text {e SST }}$ observados para os reatores UASB em dois estágios (Tabela 3 ).

No ensaio 1, a eficiência média de remoção de $\mathrm{DQO}_{\text {total }}$ no Reator 1 foi de 80,3\%. Nos ensaios 2 e 3, a eficiência de remoção de DQO $_{\text {total }}$ no Reator 1 permaneceu praticamente constante com valores de 87,7 e $89,6 \%$, respectivamente. No ensaio 4, houve aumento no valor médio da concentração de $\mathrm{DQO}_{\text {total }}$ no efluente do Reator 1 para $5.066 \mathrm{mg} \mathrm{L}^{-1}$, resultando em queda da eficiência de remoção para 74,0\% (Tabela 3). Esses valores de remoção de $\mathrm{DQO}_{\text {total }}$ no Reator 1 foram, predominantemente, superiores ou similares aos obtidos em trabalhos realizados em condições semelhantes.

TABELA 2. Valores médios da DQO total, dissolvida e devido aos sólidos suspensos, sólidos suspensos totais e voláteis dos afluentes e efluentes, tempo de detenção hidráulica $(\mathrm{TDH})$ e carga orgânica volumétrica $(\mathrm{COV})$, em relação à $\mathrm{DQO}_{\text {total }}$, obtidos durante a operação do sistema de tratamento anaeróbio, em dois estágios, Reator 1 (R1) e Reator 2 (R2), nos ensaios $1 ; 2 ; 3$ e 4.

\begin{tabular}{|c|c|c|c|c|c|}
\hline \multirow{2}{*}{ Parâmetros } & & \multicolumn{3}{|c|}{ Ensaios } & \multirow[b]{2}{*}{4} \\
\hline & & 1 & 2 & 3 & \\
\hline \multirow{2}{*}{$\mathrm{TDH} \quad$ (h) } & R1 & 62,3 & 31,1 & 62,3 & 31,1 \\
\hline & $\mathrm{R} 2$ & 12,9 & 6,5 & 12,9 & 6,5 \\
\hline \multirow{2}{*}{$\mathrm{COV}\left(\mathrm{kg} \mathrm{DQO}_{\text {total }} \mathrm{m}^{-3}\right.$ reator $\left.\mathrm{d}^{-1}\right)$} & R1 & 3,40 & 7,43 & 5,33 & 14,44 \\
\hline & $\mathrm{R} 2$ & 2,25 & 3,99 & 2,44 & 18,70 \\
\hline \multirow{3}{*}{$\mathrm{DQO}_{\text {total }}\left(\mathrm{mg} \mathrm{L}^{-1}\right)$} & Afluente & 8.818 & 9.625 & 13.844 & 18.717 \\
\hline & $\mathrm{R} 1$ & 1.207 & 1.080 & 1.309 & 5.066 \\
\hline & $\mathrm{R} 2$ & 699 & 599 & 818 & 2.667 \\
\hline \multirow{3}{*}{$\mathrm{DQO}_{\text {dissolvida }}\left(\mathrm{mg} \mathrm{L}^{-1}\right)$} & Afluente & 2.073 & 4.107 & 5.656 & 5.429 \\
\hline & $\mathrm{R} 1$ & 363 & 469 & 676 & 817 \\
\hline & $\mathrm{R} 2$ & 155 & 301 & 307 & 527 \\
\hline \multirow{3}{*}{$\mathrm{DQO}_{\mathrm{ss}}\left(\mathrm{mg} \mathrm{L}^{-1}\right)$} & Afluente & 6.745 & 5.519 & 8.188 & 13.288 \\
\hline & R1 & 844 & 611 & 633 & 4.249 \\
\hline & $\mathrm{R} 2$ & 544 & 299 & 510 & 2.141 \\
\hline \multirow{3}{*}{$\operatorname{SST}\left(\mathrm{mg} \mathrm{L}^{-1}\right)$} & Afluente & 2.216 & 2.803 & 4.300 & 7.131 \\
\hline & $\mathrm{R} 1$ & 531 & 480 & 862 & 1.700 \\
\hline & $\mathrm{R} 2$ & 300 & 332 & 534 & 864 \\
\hline \multirow{3}{*}{$\operatorname{SSV}\left(m \mathrm{gL}^{-1}\right)$} & Afluente & 1.911 & 2.545 & 3.483 & 5.806 \\
\hline & R1 & 398 & 457 & 757 & 1.403 \\
\hline & $\mathrm{R} 2$ & 230 & 289 & 455 & 701 \\
\hline
\end{tabular}

LO et al. (1994), operando reator UASB híbrido em escala de laboratório, tratando águas residuárias de suinocultura, obtiveram eficiências de remoção de DQO de $95 \%$ com concentrações de DQO $_{\text {total }}$ do afluente variando de 6,5 a $12 \mathrm{~g} \mathrm{~L}^{-1}$ e COV de 0,9 e 1,78 g DQO (L d $)^{-1}$; e eficiências de remoção de 57 a $61 \%$ com concentração de DQO do afluente de $12 \mathrm{~g} \mathrm{~L}^{-1}$ e COV de 3,58 g DQO (L d) ${ }^{-1}$. 
SÁNCHEZ et al. (1995) avaliaram o desempenho de reator UASB em um estágio, em escala de laboratório (volume de 6,5 L), tratando águas residuárias de suinocultura pré-peneiradas, por 75 dias, com COV de $5 \mathrm{~g}$ DQO $(\mathrm{L} \mathrm{d})^{-1}$. Verificaram que a composição da água residuária variou com DQO de 4.800 a $12.600 \mathrm{mg} \mathrm{L}^{-1}$ e SST de 1.900 a $3.200 \mathrm{mg} \mathrm{L}^{-1}$. No reator UASB, obteve-se $40 \%$ de eficiência de remoção de DQO.

OLIVEIRA (1997), utilizando reator UASB de bancada de 10,5 L para o tratamento de águas residuárias de suinocultura com concentrações de DQO $_{\text {total }}$ de 952 a $4.013 \mathrm{mg} \mathrm{L}^{-1}$ e de SST de 467 a $2.274 \mathrm{mg} \mathrm{L}^{-1}$, com TDH de 8 a 30 h, observou eficiências de remoção de DQO $_{\text {total }}$ de 75 a $92 \%$ e de SST de 77 a $95 \%$.

KALYUZHNYI \& SKLYAR (2000), utilizando reator UASB de bancada de 2,6 L, aplicaram COV de 4 a 6 kg DQO total $^{-3} \mathrm{~d}^{-1}$, com TDH de 24,0 a 33,6 h e águas residuárias de suinocultura com

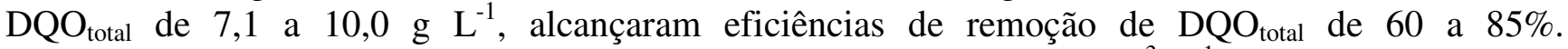
KALYUZHNYI et al. (1999) aplicaram COV de 12,39 $\mathrm{kg} \mathrm{DQO}_{\text {total }} \mathrm{m}^{-3} \mathrm{~d}^{-1}$, com o afluente com

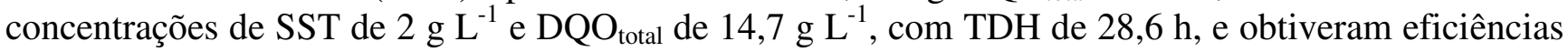
de remoção de $\mathrm{DQO}_{\text {total }}$ de $77 \%$.

Para o sistema de tratamento anaeróbio em dois estágios, as eficiências médias de remoção

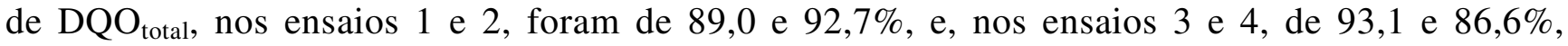
respectivamente. $\mathrm{O}$ aumento das concentrações de DQO $_{\text {total }}$ e SST do afluente com o TDH de 62,3 e 12,9 h, no primeiro e segundo reatores, respectivamente, no primeiro e terceiro ensaios, não provocou decréscimo de remoção de $\mathrm{DQO}_{\text {total }}$ e $\mathrm{DQO}_{\mathrm{ss}}$ como o que foi observado entre os ensaios 2 e 4 com a redução do TDH para 31,1 e 6,5 h no primeiro e segundo reatores, respectivamente.

OLIVEIRA (2003) avaliou o desempenho de dois reatores UASB de $705 \mathrm{~L}$, instalados em série, com TDH de 14,7 e 7,3 h, em cada reator, e COV de 2,68 a 3,86 kg DQO total $^{-3} \mathrm{~d}^{-1}$ e 11,05 a 13,77 kg $\mathrm{DQO}_{\text {total }} \mathrm{m}^{-3} \mathrm{~d}^{-1}$, respectivamente, no primeiro e segundo reatores, tratando águas residuárias de suinocultura com concentrações DQO $_{\text {total }}$ de 1.643 a $4.189 \mathrm{mg} \mathrm{L}^{-1}$ e SST de 1.338 a $2.166 \mathrm{mg} \mathrm{L}^{-1}$. Obteve eficiências médias de remoção de DQO $_{\text {total }}$ e SST de 83\%, com o maior TDH, e de 71 a $81 \%$, com o menor TDH.

TABELA 3. Valores médios das eficiências de remoção de DQO, SST e SSV, porcentagem de $\mathrm{CH}_{4}$ no biogás e das produções volumétrica e específica de $\mathrm{CH}_{4}$ obtidos durante a operação do sistema de tratamento anaeróbio, em dois estágios, Reator 1 (R1) e Reator 2 (R2), e no conjunto Reator $1+$ Reator $2(\mathrm{R} 1+\mathrm{R} 2)$, nos ensaios $1 ; 2 ; 3$ e 4

\begin{tabular}{|c|c|c|c|c|c|c|c|c|c|}
\hline \multirow{3}{*}{ Ensaios } & \multirow{3}{*}{ Reator } & \multicolumn{5}{|c|}{ Eficiência de remoção (\%) } & \multirow{3}{*}{$\begin{array}{c}\mathrm{CH}_{4} \\
(\%)\end{array}$} & \multirow{3}{*}{$\begin{array}{c}\text { Produção } \\
\text { Volumétrica } \\
\left(\mathrm{m}^{3} \mathrm{CH}_{4} \mathrm{~m}^{-3}\right. \\
\left.\text { reator } \mathrm{d}^{-1}\right)\end{array}$} & \multirow{3}{*}{$\begin{array}{c}\text { Produção } \\
\text { Específica } \\
\left(\mathrm{m}^{3} \mathrm{CH}_{4} \mathrm{~kg}^{-1} \mathrm{DQO} \mathrm{O}_{\text {tota }}\right. \\
\text { removida })\end{array}$} \\
\hline & & \multirow[b]{2}{*}{ Total } & \multicolumn{2}{|l|}{ DQO } & \multicolumn{2}{|c|}{ Sólidos Suspensos } & & & \\
\hline & & & Dissolv. & SS & Totais & Voláteis & & & \\
\hline \multirow{3}{*}{1} & $\mathrm{R} 1$ & 80,3 & 80,2 & 82,3 & 72,8 & 75,4 & 81,0 & 0,594 & 0,335 \\
\hline & $\mathrm{R} 2$ & 44,8 & 57,2 & 51,0 & 44,3 & 46,1 & 84,0 & 0,160 & 0,276 \\
\hline & $\mathrm{R} 1+\mathrm{R} 2$ & 89,0 & 91,4 & 89,7 & 86,5 & 88,2 & - & 0,754 & 0,289 \\
\hline \multirow{3}{*}{2} & R1 & 87,7 & 87,2 & 85,1 & 81,4 & 79,7 & 78,9 & 0,899 & 0,158 \\
\hline & $\mathrm{R} 2$ & 40,5 & 37,6 & 59,0 & 30,4 & 34,7 & 82,9 & 0,333 & 0,176 \\
\hline & $\mathrm{R} 1+\mathrm{R} 2$ & 92,7 & 91,8 & 92,6 & 87,8 & 87,8 & - & 1,232 & 0,210 \\
\hline \multirow{3}{*}{3} & R1 & 89,6 & 88,0 & 91,8 & 80,1 & 75,4 & 76,5 & 0,742 & 0,133 \\
\hline & $\mathrm{R} 2$ & 34,3 & 50,5 & 34,6 & 33,6 & 37,3 & 83,3 & 0,144 & 0,230 \\
\hline & $\mathrm{R} 1+\mathrm{R} 2$ & 93,1 & 94,4 & 89,1 & 87,3 & 85,6 & - & 0,886 & 0,213 \\
\hline \multirow{3}{*}{4} & $\mathrm{R} 1$ & 74,0 & 84,9 & 69,4 & 73,4 & 73,5 & 77,0 & 1,130 & 0,170 \\
\hline & $\mathrm{R} 2$ & 45,1 & 32,9 & 43,5 & 46,0 & 47,6 & 79,9 & 0,513 & 0,077 \\
\hline & $\mathrm{R} 1+\mathrm{R} 2$ & 86,6 & 90,5 & 85,0 & 85,6 & 86,7 & - & 1,643 & 0,156 \\
\hline
\end{tabular}


PEREIRA (2003), utilizando reatores UASB em dois estágios, em escala de bancada com volumes de 39,8 e 10,5 L, no tratamento de águas residuárias de suinocultura, com concentrações médias de SST de 5.000 a $5.490 \mathrm{mg} \mathrm{L}^{-1}$ e DQO total variando de 11.740 a $12.306 \mathrm{mg} \mathrm{L}^{-1}$, com TDH de 62; 31 e 16 h e COV de 4,55; 8,75 e 18,65 $\mathrm{kg}$ DQO m$^{-3}$ reator d $\mathrm{d}^{-1}$ no primeiro reator, obteve eficiências médias de remoção de $\mathrm{DQO}_{\text {total }}$ de 95; 92 e 79\%, para o conjunto de reatores, respectivamente.

Neste trabalho, nos ensaios 2; 3 e 4, nos quais as concentrações de $\mathrm{DQO}_{\text {total }}$ do afluente foram próximas às obtidas por PEREIRA (2003), com valores médios de 9.625 a $18.717 \mathrm{mg} \mathrm{L}^{-1}$, observou-se também que com o aumento da COV de 7,43 e 5,33 para 14,44 $\mathrm{kg} \mathrm{DQO}_{\text {total }} \mathrm{m}^{-3}$ reator $\mathrm{d}^{-1}$, no Reator 1 , e a diminuição do TDH de 62,3 para $31,1 \mathrm{~h}$, no Reator 1 , e de 12,9 para $6,5 \mathrm{~h}$, no Reator 2 , houve queda nas eficiências de remoção de DQO total, DQO dissolvida e DQO devido à fração dos sólidos suspensos, de valores em torno de $92 \%$ para valores próximos a $86 \%$ (Tabela 3 e Figura 2).

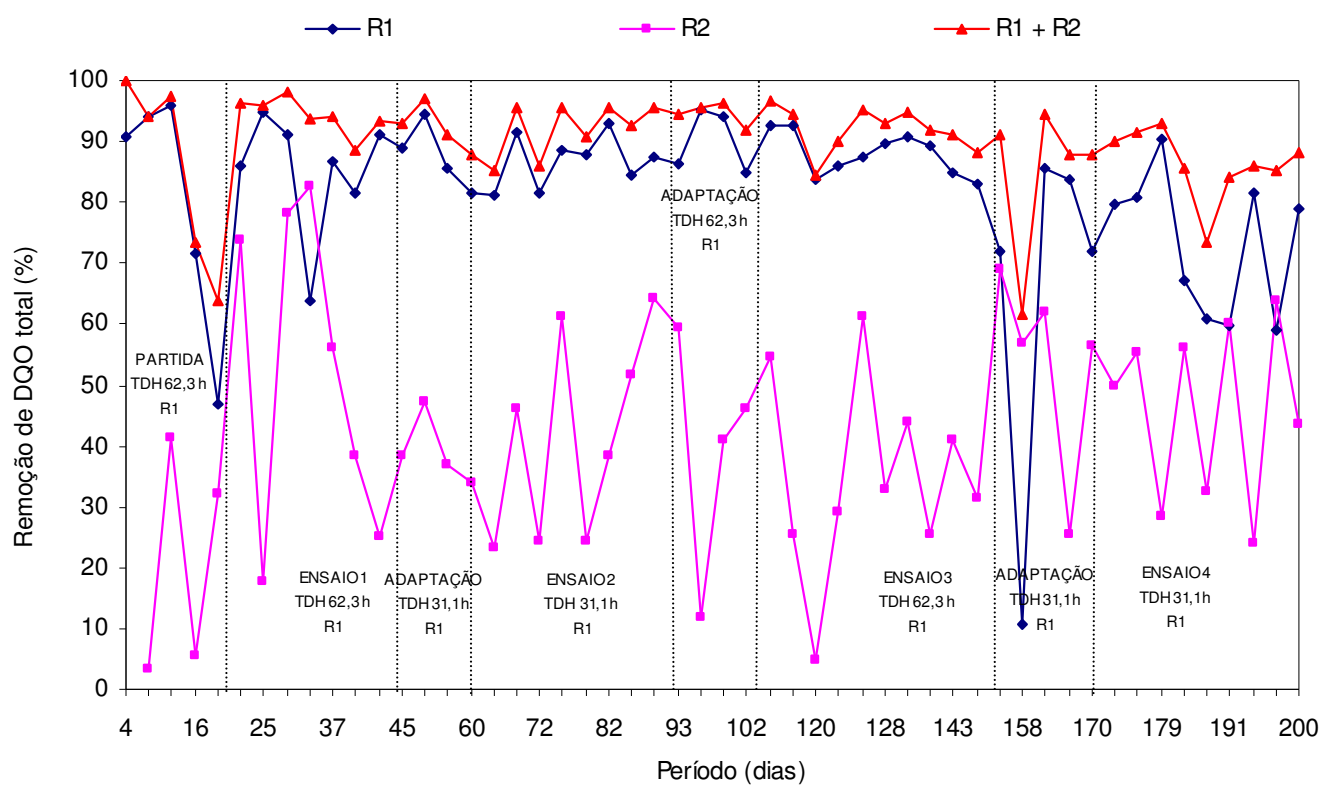

FIGURA 2. Valores das eficiências de remoção de $\mathrm{DQO}_{\text {total }}$ no Reator 1 (R1), Reator 2 (R2) e conjunto $\mathrm{R} 1+\mathrm{R} 2$.

Esse comportamento observado indicou que, para a COV na faixa de 3,40 a 7,43 $\mathrm{kg} \mathrm{DQO}_{\text {total }} \mathrm{m}^{-3}$ reator $\mathrm{d}^{-1}$, e TDH acima de $31 \mathrm{~h}$ no Reator 1 , pôde-se obter eficiência de remoção de $\mathrm{DQO}_{\text {total }}$ em torno de $90 \%$ para o conjunto de reatores $(\mathrm{R} 1+\mathrm{R} 2)$. Para a COV média de $14,44 \mathrm{~kg} \mathrm{DQO}_{\text {total }} \mathrm{m}^{-3}$ reator d $\mathrm{d}^{-1}$, verificou-se influência da aplicação do TDH de 31,1 h, no Reator 1, com a eficiência diminuindo para valores médios em torno de 85\%, para o conjunto de reatores (R1 + R2). PEREIRA (2003) também observou decréscimo na eficiência média de remoção de $\mathrm{DQO}_{\text {total }}$ (de 92 para 79\%) quando aumentou a COV de 8,75 para $18,65 \mathrm{~kg} \mathrm{DQO}_{\text {total }} \mathrm{m}^{-3} \mathrm{~d}^{-1}$, com a diminuição do TDH de 31 para $16 \mathrm{~h}$, no primeiro reator.

Os valores médios da $\mathrm{DQO}_{\text {dissolvida }}$ do efluente do Reator 1, nos ensaios 1 ao 4, aumentaram, respectivamente, de 363 para $817 \mathrm{mg} \mathrm{L}^{-1}$, apresentando, contudo, variação na eficiência de remoção de DQO $_{\text {dissolvida, de }} 80,2$ a 88,0\%. Para o conjunto de reatores $(\mathrm{R} 1+\mathrm{R} 2)$, a remoção de $\mathrm{DQO}_{\text {dissolvida }}$ variou de $90,5 \%$ a $94,4 \%$.

HENN \& BELLI FILHO (2000) avaliaram o desempenho de um reator UASB em escala de bancada, com volume de $8 \mathrm{~L}$, com TDH de $36 \mathrm{~h}$, tratando dejetos de suínos com DQO do afluente de 5.000 a $25.000 \mathrm{mg} \mathrm{L}^{-1}$ e ST de $8.000 \mathrm{mg} \mathrm{L}^{-1}$. Verificaram que o reator atingiu eficiências médias de remoção de $\mathrm{DQO}_{\text {total }}$ e $\mathrm{DQO}_{\text {dissolvida }}$ da ordem de $80 \%$ e $90 \%$, respectivamente. 
OLIVEIRA (2003) operou dois reatores UASB, instalados em série, com COV de 11,05 a $13,77 \mathrm{~kg} \mathrm{DQO}_{\text {total }} \mathrm{m}^{-3}$ reator $\mathrm{d}^{-1}$, no primeiro reator, e observou eficiência de remoção de $\mathrm{DQO}_{\text {dissolvida }}$ para o conjunto de reatores $(\mathrm{R} 1+\mathrm{R} 2)$ de 55 a 67\%. RAMIREZ et al. (2002) avaliaram o desempenho de um sistema constituído por um reator UASB, seguido de filtro anaeróbio, com TDH de 4 e $14 \mathrm{~h}$, respectivamente, tratando águas residuárias de suinocultura, e obtiveram eficiência de remoção no sistema UASB-filtro de 79,2\% para a DQO solúvel. PEREIRA (2003) observou eficiências médias de remoção de $\mathrm{DQO}_{\text {dissolvida }}$ de 88; 86 e 76\%, com a redução do TDH para 78; 39 e 20 h, respectivamente, nos reatores UASB, em dois estágios.

A DQO, devido à fração de sólidos suspensos $\left(\mathrm{DQO}_{\mathrm{ss}}\right)$, resultante da diferença entre a $\mathrm{DQO}_{\text {total }} \mathrm{e}$ dissolvida, correspondeu na média de 71,0 e 76,5\% da $\mathrm{DQO}_{\text {total }}$ do afluente do Reator 1 para os ensaios 1 e 4, respectivamente, resultados similares aos obtidos por OLIVEIRA (1997) e PEREIRA (2003), que trabalharam com águas residuárias de suinocultura em reator UASB e obtiveram DQO ss $_{\text {entre }} 66$ e $80 \%$ e 70 e $75 \%$, respectivamente. Para os ensaios 2 e 3, a fração da $\mathrm{DQO}_{\text {ss }}$ em relação à $\mathrm{DQO}_{\text {total }}$ correspondeu, na média, a 57,3 e 59,1\%, respectivamente. Essa diminuição na participação da $\mathrm{DQO}_{\mathrm{ss}}$, na $\mathrm{DQO}_{\text {total }}$, pode ser atribuída às variações na quantidade de sólidos dos diferentes lotes de esterco bruto utilizados para a preparação do afluente do Reator 1, em virtude de alterações na idade dos animais, na composição da ração ou da época do ano.

A eficiência média de remoção de $\mathrm{DQO}_{\text {ss }}$, no Reator 1, variou de 69,4 a 91,8\%, apresentando menores valores no ensaio 4, como ocorreu para $\mathrm{DQO}_{\text {total. }}$ Para o conjunto de reatores $(\mathrm{R} 1+\mathrm{R} 2)$, a remoção da $\mathrm{DQO}_{\mathrm{ss}}$ variou de 85,0 a 92,6\%.

KALYUZHNYI et al. (1999), utilizando reator UASB, aplicaram COV de 4 a 6 kg DQO total $\mathrm{m}^{-3} \mathrm{~d}^{-1}$, com TDH de 24,0 a 33,6 h, e afluente, pré-acidificado ou filtrado, com DQO ss de 0,6 a $2,1 \mathrm{~g} \mathrm{~L}^{-1}$, e alcançaram eficiências de remoção de $\mathrm{DQO}_{\mathrm{ss}}$ de 67 a $89 \%$.

OLIVEIRA (2003) verificou, nos dois reatores UASB instalados em série, que, com TDH de $29,4 \mathrm{~h}$, a eficiência de remoção de $\mathrm{DQO}_{\text {ss }}$ foi de $88 \%$, com temperatura média de $22,2^{\circ} \mathrm{C}$, e com TDH de 14,6 h diminuiu para $74 \%$ e $85 \%$, respectivamente, com temperaturas médias de 19,8 e $24,9^{\circ} \mathrm{C}$.

No Reator 2, nos quatro ensaios, houve aumento nos valores médios da $\mathrm{DQO}_{\text {total }}$ do efluente de 599 para $2.667 \mathrm{mg} \mathrm{L}^{-1} \mathrm{e}$, conseqüentemente, queda da eficiência de remoção, do ensaio 1 para o ensaio 3 , de 44,8 para $34,3 \%$. No ensaio 4 , houve aumento de eficiência para 45,1\%. Com a diminuição do TDH de 12,9 para 6,5 h, observou-se, no efluente do Reator 2, aumento nos valores médios de DQO $_{\text {dissolvida }}$ de 155 para $301 \mathrm{mg} \mathrm{L}^{-1}$, e de 307 para $527 \mathrm{mg} \mathrm{L}^{-1}$, respectivamente, nos ensaios 1 e 2 , e 3 e 4, resultando em queda de eficiência de remoção de 57,2 para 37,6\% e de 50,5 para 32,9\%, respectivamente. A eficiência média de remoção de $\mathrm{DQO}_{\mathrm{ss}}$, no Reator 2, apresentou variações acentuadas, de $34,6 \%$ a $59,0 \%$.

As cargas orgânicas volumétricas (COV) aplicadas no Reator 1 variaram, na média, de 3,40 a $14,44 \mathrm{~kg} \mathrm{DQO}_{\text {total }} \mathrm{m}^{-3}$ reator $\mathrm{d}^{-1}$ e de 2,25 a $18,70 \mathrm{~kg} \mathrm{DQO}_{\text {total }} \mathrm{m}^{-3}$ reator $\mathrm{d}^{-1}$ no Reator 2 . Esses valores de COV não foram limitantes para a obtenção de altas eficiências de remoção de DQO no conjunto Reator 1 + Reator 2, as quais variaram, na média, de 85,0 a 94,4\%. Os menores valores de eficiência de remoção de $\mathrm{DQO}_{\text {total }}(86,6 \%)$, DQO dissolvida $(90,5 \%)$ e $\mathrm{DQO}_{\mathrm{ss}}(85,0 \%)$ foram observados no ensaio 4, com as maiores COV aplicadas, de 14,44 $\mathrm{kg} \mathrm{DQO}_{\text {total }} \mathrm{m}^{-3}$ reator d $\mathrm{d}^{-1}$ no Reator $1 \mathrm{e} 18,70 \mathrm{~kg} \mathrm{DQO}_{\text {total }}$ $\mathrm{m}^{-3}$ reator $\mathrm{d}^{-1}$ no Reator 2 .

As eficiências médias de remoção de SST, nos ensaios $1 ; 2 ; 3$ e 4 do experimento, no Reator 1 , foram, respectivamente, de 72,2; 81,4; 80,1 e 73,3\%; e, no Reator 2, de 44,3; 30,4; 33,6 e 46,0\% (Tabela 3). Para SSV, as eficiências médias de remoção, nos quatro ensaios, foram, respectivamente, 46,$1 ; 34,7 ; 37,3$ e 47,6\%. Com a diminuição do TDH, no ensaio 2, observou-se queda da eficiência de remoção de sólidos suspensos, no Reator 2, ocorrida em conseqüência do aumento do arraste de 
sólidos no sistema de tratamento provocado pela diminuição do TDH e aumento na produção de biogás.

Observou-se que a eficiência média de remoção de SST e SSV do sistema de tratamento anaeróbio, em dois estágios $(\mathrm{R} 1+\mathrm{R} 2)$, foi alta e manteve-se praticamente constante durante os ensaios do experimento, com valores médios variando de 85,6 a 87,8\% para SST e de 85,6 a 88,2\% para SSV. Verificou-se, no ensaio 4, a diminuição da eficiência média de remoção de sólidos suspensos no Reator 1, enquanto, no Reator 2, aumentava (Tabela 3), absorvendo as variações de carga impostas na saída do Reator 1, mantendo, assim, estável a eficiência do sistema de tratamento em dois estágios (Figura 3).

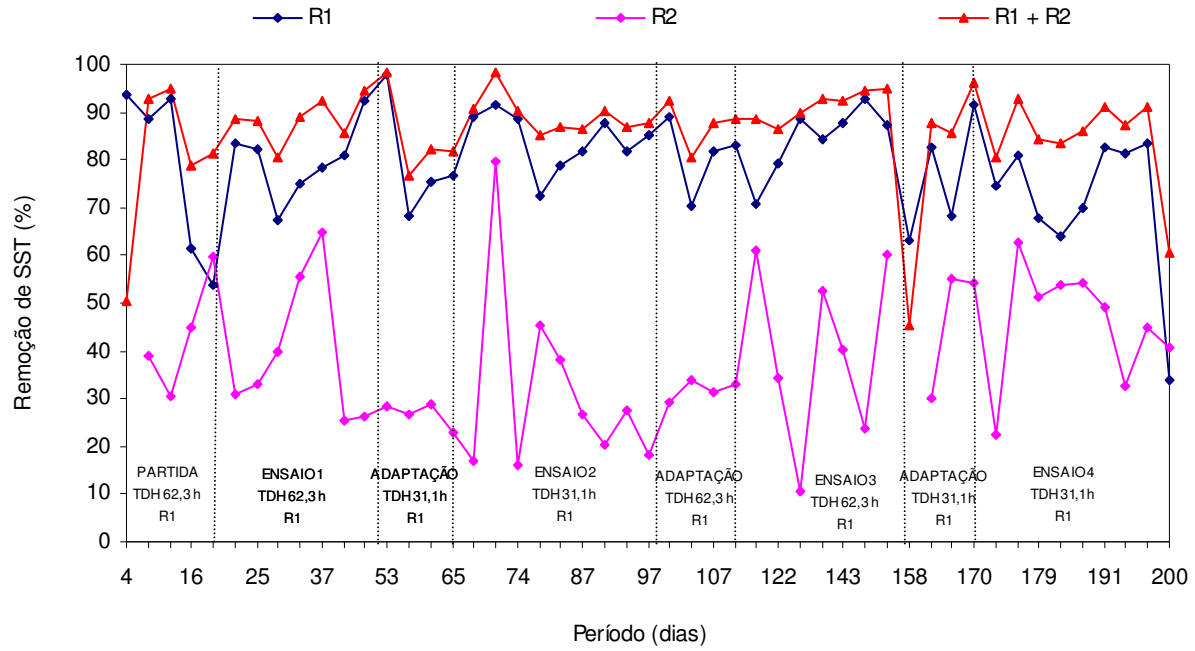

FIGURA 3. Valores das eficiências de remoção de SST no Reator 1 (R1), Reator 2 (R2) e conjunto R1 $+\mathrm{R} 2$.

IAMAMOTO (1999) operou dois reatores UASB de $705 \mathrm{~L}$, instalados em série, com o afluente com concentração de DQO de 1,05 a 3,25 $\mathrm{g} \mathrm{L}^{-1}$ e SST de 0,34 a 1,74 g L ${ }^{-1}$, com COV variando de 1,05 a 5,31 g DQO L d ${ }^{-1}$ e TDH de 23,5 e 14,7 h, no primeiro reator, obtendo eficiências de remoção de DQO no conjunto dos reatores de 69 a 82\% e de SST de 66 a 93\%. A associação em série dos dois reatores UASB diminuiu o efeito do arraste de sólidos do primeiro reator, que foi acomodado no segundo reator, mantendo estável a eficiência do sistema de tratamento. Esse mesmo comportamento foi observado por OLIVEIRA (2001 e 2003) e PEREIRA (2003).

Verificou-se, a partir dos resultados obtidos para as eficiências de remoções de DQO e SST para o conjunto Reator 1 + Reator 2, a vantagem de usar o sistema de tratamento anaeróbio em dois estágios, em relação ao tratamento em estágio único, no qual o segundo reator trabalhou acomodando as variações de eficiência do primeiro reator, melhorando a qualidade do efluente final, proporcionando maior estabilidade, eficiência e melhor estabilização da matéria orgânica.

Comparando o desempenho do sistema de tratamento anaeróbio em um estágio, representado pelo Reator 1, com TDH de 62,3 h, nos ensaios 1 e 3, com o sistema em dois estágios, representado pelo conjunto Reator 1 + Reator 2, com TDH total de 37,6 h, nos ensaios 2 e 4, observou-se que, mesmo com TDH menor no sistema, em dois estágios, as eficiências de remoção de DQO e sólidos suspensos foram mais estáveis (Figuras 2 e 3) e superiores (Tabela 3), exceto para DQO $_{\text {total }}$ e DQO ss $_{\text {so }}$ ensaio 4, com valores inferiores, sendo $86,6 \%$ contra $89,6 \%$ e $85,0 \%$ contra $91,8 \%$, respectivamente. A vantagem do sistema em dois estágios pode ser verificada com maior evidência para a remoção de DQO $_{\text {dissolvida, }}$ cujos valores no sistema, em dois estágios, foram sempre superiores, considerando a maior dificuldade de remoção das frações dissolvidas liberadas pelo primeiro reator. Para a produção volumétrica de metano, verificou-se, também, maiores valores para o sistema em dois estágios. 
Os resultados obtidos por OLIVEIRA (2003) e PEREIRA (2003) são semelhantes aos obtidos neste estudo, com eficiências médias de remoção de DQO e SST no sistema de tratamento anaeróbio em dois estágios, na faixa de 71 a 95\%. Embora no Reator 2 tenha-se observado menor eficiência de remoção da matéria orgânica, houve contribuição para os acréscimos e estabilidade da eficiência de remoção do sistema estudado. Isso pode ser observado com maior evidência com a maior COV aplicada, no ensaio 4, quando, no Reator 1, houve queda de eficiência em termos de remoção de $\mathrm{DQO}_{\text {total }}, \mathrm{DQO}_{\text {dissolvida, }}, \mathrm{DQO}_{\mathrm{ss}}$, SST e SSV e, no Reator 2, houve aumento da eficiência de remoção de DQO $_{\text {total}}$, DQO $_{\text {ss, }}$ SST e SSV, absorvendo as variações de carga impostas pelo aumento das concentrações de matéria orgânica solúvel e particulada na saída do primeiro reator.

CHERNICHARO (1997) considera o sistema anaeróbio eficiente para o tratamento de águas residuárias, quando a remoção de matéria orgânica for superior a $65 \%$.

Os teores médios de $\mathrm{CH}_{4}$ no biogás, no Reator 2, foram superiores aos do Reator 1, durante os quatros ensaios, variando de 79,9 a $84,0 \%$ e de 76,5 a $81,0 \%$, respectivamente (Tabela 3). Com o aumento da $\mathrm{COV}$, observou-se tendência de diminuição na porcentagem de $\mathrm{CH}_{4}$ no biogás dos dois reatores, porém permanecendo acima de $75 \%$, demonstrando boa estabilidade nos reatores e o nãocomprometimento da atividade da microbiota do lodo na conversão da matéria orgânica a metano.

A produção volumétrica média de $\mathrm{CH}_{4}$ aumentou com o aumento da $\mathrm{COV}$ (Tabela 3 e Figura 4), variando de 0,594 a $1,130 \mathrm{~m}^{3} \mathrm{CH}_{4} \mathrm{~m}^{-3}$ reator $\mathrm{d}^{-1}$ e 0,160 a $0,513 \mathrm{~m}^{3} \mathrm{CH}_{4} \mathrm{~m}^{-3}$ reator $\mathrm{d}^{-1}$, respectivamente, nos Reatores 1 e 2 . As maiores produções específicas de $\mathrm{CH}_{4}$ foram observadas no ensaio 1, com valores de 0,335; 0,276 e $0,289 \mathrm{~m}^{3} \mathrm{CH}_{4} \mathrm{~kg}^{-1} \mathrm{DQO}_{\text {total }}$ removida, respectivamente, para os Reatores 1 e 2, e o conjunto Reator 1 + Reator 2. Observou-se que, com o aumento da COV e diminuição do TDH, houve diminuição da produção específica de metano no conjunto de reatores.

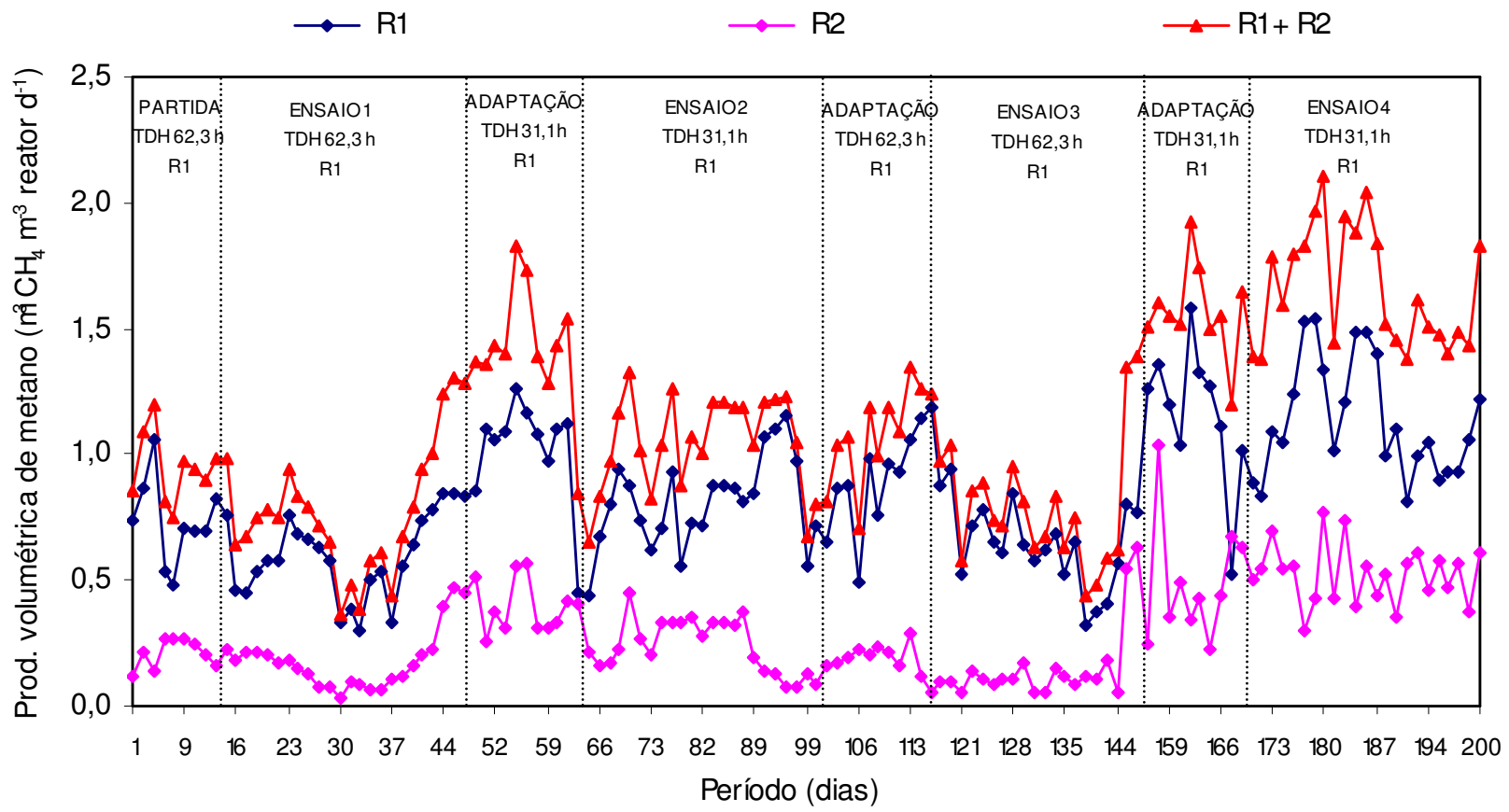

FIGURA 4. Valores da produção volumétrica de metano no Reator 1(R1), Reator 2 (R2) e conjunto R1 $+\mathrm{R} 2$.

PEREIRA (2003) obteve valores médios similares de produção volumétrica de 0,60 e 1,42 $\mathrm{m}^{-3}$ $\mathrm{CH}_{4} \mathrm{~m}^{-3}$ reator $\mathrm{d}^{-1}$, nos reatores UASB em dois estágios, em escala de bancada, tratando águas residuárias de suinocultura com $\mathrm{DQO}_{\text {total }}$ de 11.740 e $11.292 \mathrm{mg} \mathrm{L}^{-1}$, respectivamente, aplicando COV de 4,55 e 8,75 kg DQO $\mathrm{ktal} \mathrm{m}^{-3}$ reator $\mathrm{d}^{-1}$, no Reator 1 . 
Na Figura 5, estão apresentadas as variações de pH, alcalinidade total (AT) e ácidos voláteis totais (AVT) no decorrer do experimento, nos Reatores 1 e 2.

Os valores médios de $\mathrm{pH}$ no afluente variaram de 5,0 a 7,7. Nos efluentes dos reatores, o pH variou de 6,9 a 8,3. Segundo LETTINGA (1995), a maioria dos sistemas de tratamento anaeróbio é operada na faixa de $\mathrm{pH}$ entre 6,5 e 7,5, recomendando a manutenção de $\mathrm{pH}$ maior do que 6,2.

No efluente do Reator 1, observaram-se os menores valores de $\mathrm{pH}$. Esses resultados indicam maior produção de ácidos orgânicos no Reator 1, em decorrência da maior atividade das bactérias hidrolíticas e acidogênicas do que no Reator 2. Os valores médios de $\mathrm{pH}$ encontrados situaram-se dentro da faixa ótima para a degradação anaeróbia $(6,6$ a 7,4), não atingindo valores considerados prejudiciais à atividade das arqueas metanogênicas (LETTINGA, 1995).
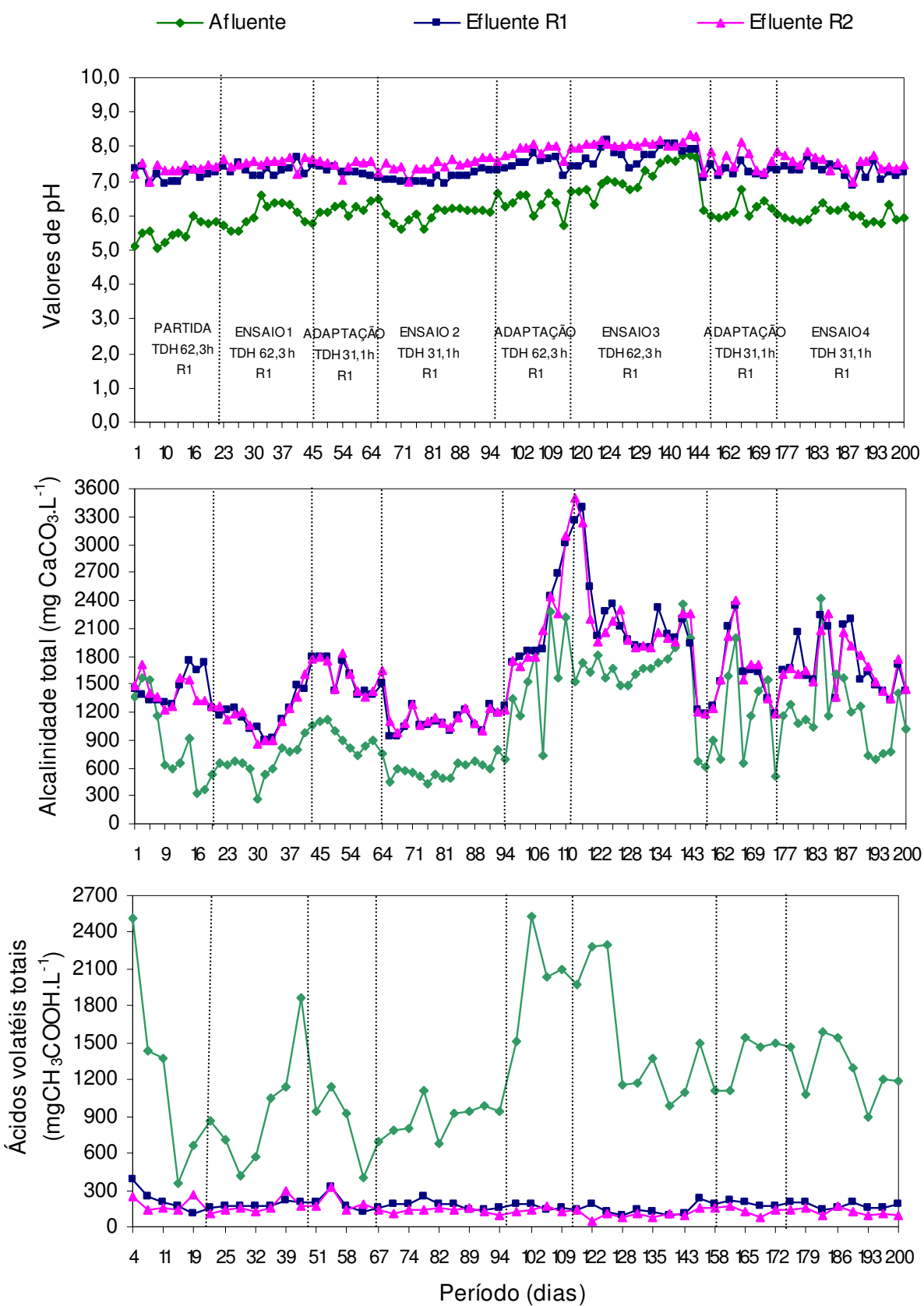

FIGURA 5. Valores de $\mathrm{pH}$, alcalinidade total (AT) e ácidos voláteis totais (AVT) do afluente e efluentes dos Reatores 1 e 2 durante os ensaios $1 ; 2 ; 3$ e 4. 
Os valores de AT aumentaram do afluente para o efluente. Observaram-se valores entre 888 e $3.400 \mathrm{mg} \mathrm{CaCO}_{3} \mathrm{~L}^{-1}$ e entre 848 e $3.492 \mathrm{mg} \mathrm{CaCO}_{3} \mathrm{~L}^{-1}$ para os efluentes dos Reatores 1 e 2, respectivamente. Os valores de AT nos efluentes dos Reatores 1 e 2 foram similares em todos os ensaios do experimento. Houve decréscimo de AT nos efluentes dos Reatores 1 e 2 com a diminuição do TDH.

A concentração de ácidos voláteis totais (AVT) é um parâmetro de extrema importância para a digestão anaeróbia. Os ácidos graxos voláteis devem estar em equilíbrio com a alcalinidade do sistema. A inibição do processo anaeróbio por ácidos graxos voláteis está associada ao pH. Baixos valores de pH estão geralmente relacionados a altas concentrações de ácidos graxos voláteis e, conseqüentemente, à falência do processo (KUS \& WIESMANN, 1995).

A concentração de AVT no afluente do Reator 1 variou de 825 a $1.648 \mathrm{mg} \mathrm{L}^{-1}$ e, no efluente, houve decréscimo para valores médios na faixa de 167 a $169 \mathrm{mg} \mathrm{L}^{-1}$. No efluente do Reator 2 , diminuiu para valores médios em torno de $142 \mathrm{mg} \mathrm{L}^{-1}$, mesmo com a diminuição do TDH e aumento da COV. Esse comportamento dos AVT e da AT indicou estabilidade dos reatores com geração de alcalinidade, melhorando a capacidade de tamponamento do reator e não permitindo o acúmulo de ácidos voláteis.

Os valores de AVT nos Reatores 1 e 2 mantiveram-se abaixo do valor recomendado de $200 \mathrm{mg} \mathrm{L}^{-1}$, o que indicou condições de estabilidade do processo, segundo LETTINGA (1995), confirmando as condições favoráveis para a atividade microbiana do lodo e propiciando os bons resultados de desempenho do conjunto Reator 1 e Reator 2 para a remoção de DQO, sólidos suspensos e produção de metano.

\section{CONCLUSÕES}

O sistema de tratamento em dois estágios foi eficiente na remoção de DQO e sólidos suspensos, com valores médios acima de $85 \%$ e conversões acima de $0,15 \mathrm{~m}^{3} \mathrm{CH}_{4} \mathrm{~kg}^{-1} \mathrm{DQO}_{\text {total }}$ removida.

Considerando-se o sistema de tratamento com reatores UASB em dois estágios, o TDH de 37,6 h foi mais eficiente para a remoção de DQO e SS, e para a produção de metano, do que o reator UASB em um estágio com TDH de 62,3 h e COV de 3,40 e 5,33 $\mathrm{kg} \mathrm{DQO}_{\text {total }} \mathrm{m}^{-3}$ reator por dia.

O principal parâmetro de projeto para afluentes com concentrações médias de SST variando de 2.216 a $7.131 \mathrm{mg} \mathrm{L}^{-1}$ é a COV e não a concentração de SST do afluente ou TDH.

As maiores produções específicas de metano foram obtidas com valores de COV de 3,40 kg $\mathrm{DQO}_{\text {total }} \mathrm{m}^{-3}$ reator $\mathrm{d}^{-1}$ para Reator 1 e $2,25 \mathrm{~kg} \mathrm{DQO}_{\text {total }} \mathrm{m}^{-3}$ reator por dia para o Reator 2, com TDH de 62,3 h no Reator 1 , enquanto os maiores valores de produção volumétrica de $\mathrm{CH}_{4}$ foram observados no ensaio 4, com maiores valores de COV 14,44 $\mathrm{kg} \mathrm{DQO}_{\text {total }} \mathrm{m}^{-3}$ reator por dia para o Reator 1 e $18,70 \mathrm{~kg}$ $\mathrm{DQO}_{\text {total }} \mathrm{m}^{-3}$ reator por dia para o Reator 2 .

\section{AGRADECIMENTOS}

À FAPESP e à TIGRE S.A. Tubos e conexões, pelo apoio financeiro.

\section{REFERÊNCIAS}

APHA, AWWA, WPCF. Standard methods for the examination of water and wastewater. $15^{\text {th }}$ ed. Washington, 1992. $1.268 \mathrm{p}$.

CHERNICHARO, C.A.L. de. Reatores anaeróbios: princípios do tratamento biológico de águas residuárias. Belo Horizonte: Polytécnica, 1997. 246 p. 
DILALLO, R.; ALBERTSON, O.E. Volatile acids by direct titration. Journal Water Pollution Control Federation, Alexandria, v.33, n.4, p.356-35, 1961.

FORESTI, E. Fundamentos do processo de digestão anaeróbia. In: TALLERY SEMINARIO LATONOAMERICANO TRATAMIENTO ANAEROBIO DE AGUAS RESIDUALES, 3., 1994, Montevidéu, Uruguai. Anais... p.97-110.

HENN, A.; BELLI FILHO, P. Tratamento de dejetos de suínos com altas concentrações de DQO e de sólidos em reatores UASB. In: SIMPÓSIO INTERNACIONAL DE INICIAÇÃO CIENTÍFICA DA UNIVERSIDADE DE SÃO PAULO, 8., 2000, São Paulo. Anais... São Paulo: USP, 2000. v.2, p.150.

IAMAMOTO, C.Y. Efeito da taxa de carregamento orgânico volumétrico no desempenho de reatores anaeróbios de fluxo ascendente com manta de lodo tratando águas residuárias de suinocultura. 1999. 104 f. Dissertação (Mestrado em Gestão Integrada de Recursos) - Centro de Estudos Ambientais, Universidade Estadual Paulista, Rio Claro, 1999.

ISHIZUKA, M.M. A biotecnologia no tratamento de dejetos de suínos. Disponível em: $<$ http://www.cnpsa.embrapa.br>. Acesso em: 3 jun. 2003.

KALYUZHNYI, S.; SKLYAR, V.; FEDOROVICH, V.; KOVALEV, A; NOZHEVNIKOVA, A.; KLAPWIJK, A. The development of biological methods for utilization and treatment of diluted manure streams. Water Science and Technology, Kidlington, v.40, n.1, p.223-30, 1999.

KALYUZHNYI, S.; SKLYAR, V. Integrated mechanical, biological and physic-chemical treatment of liquid manure streams. Water Science and Technology, Kidlington, v.41, n.12, p.182-88, 2000.

KUS, F.; WIESMANN, U. Degradation kinetics of acetate and propionate by immobilized anaerobic mixed cultures. Water Research, Exceter, v.29, n.6, p.1437-43, 1995.

LETTINGA, G.; VELSEN, A.F.M. Van; HOBMA, S.M; ZEEUW, W.; KLAPWIJC, A. Use of the upflow sludge blanket (USB) reactor concept for biological wastewater especially anaerobic treatment. Biotechnology and Bioengineering, New York, v.22, n.4, p.699-734, 1980.

LETTINGA, G.; HULSHOFF-POL, L.W. UASB - Process design for various types of wastewaters. Water Science and Technology, Kidlington, v.24, n.8, p.87-107, 1991.

LETTINGA, G. Anaerobic and wastewater treatment systems. Antonie van leeuwenhoek, Dordrecht, v.67, p.3-28, 1995.

LIER, J.B. Van; TILCHE, A.; AHRING, B.K.; MACARIE, H.; MOLETTA,R.; DOHANYOS, M.; HULSHOFF POL, L.W.; LENS, P.; VERSTRAETE, W.. New perspectives in anaerobic digestion. Water Science and Technology, Kidlington, v.43, n.1, p.1-18, 2001.

LO, K.V.; LIAO, P.H.; GAO, Y.C. Anaerobic treatment of swine wastewater using hybrid UASB reactors. Bioresource Technology, Kidlington, v.47, p.153-7, 1994.

OLIVEIRA, P.A.V.; COSTA, R.H.R.; TROGLIO, J. Lagoons for treatment of waste products from hogs: example of Coopercentral. In: INTERNATIONAL CONFERENCE AND WORKSHOP ON WATE STABILIZATION PONDS TECHNOLOGY AND APPLICATIONS, 3., 1995, João Pessoa. Proceedings... João Pessoa: IAWQ, 1995. 6 p.

OLIVEIRA, R.A. de. Efeito da concentração de sólidos suspensos do afluente no desempenho e características do lodo de reatores anaeróbios de fluxo ascendente com manta de lodo tratando águas residuárias de suinocultura.1997. 389 f. Tese (Doutorado em Hidráulica e Saneamento) - Escola de Engenharia de São Carlos, Universidade de São Paulo, São Carlos, 1997.

OLIVEIRA, R.A.; CAMPELO, P.G.; MATOS, A.T.; MARTINEZ, M.A.; CECON, P.R. Influência da aplicação de águas residuárias de suinocultura na capacidade de infiltração de um solo Podzólico 
Vermelho-Amarelo. Revista Brasileira de Engenharia Agrícola Ambiental, Campina Grande, v.4, n.2, p.263-7, 2000.

OLIVEIRA, R.A. de. Efeito da carga hidráulica volumétrica, da temperatura climatológica e do descarte do excesso de lodo da manta no desempenho de reatores UASB tratando águas residuárias de suinocultura. Jaboticabal: FCAV/UNESP, 2001. 125 p. (Relatório final de pesquisa CPA/UNESP)

OLIVEIRA, R.A. de. Efeito da temperatura e do descarte de lodo no desempenho de reatores anaeróbios de fluxo ascendente com manta de lodo, em série, tratando águas residuárias de suinocultura. In: CONGRESSO BRASILEIRO DE ENGENHARIA AGRÍCOLA, 32., 2003, Goiânia. Anais... Jaboticabal: Sociedade Brasileira de Engenharia Agrícola, 2003. 1 CD-ROM.

PEREIRA, E.R. Desempenho e caracterização microbiana do processo de dois estágios com reatores anaeróbios de fluxo ascendente com manta de lodo (UASB) tratando águas residuárias de suinocultura. 2003. 103 f. Dissertação (Mestrado em Hidráulica e Saneamento) - Escola de Engenharia de São Carlos, Universidade de São Paulo, São Carlos, 2003.

RAMIREZ, O.P.; ARTUNES, R.M; QUADRO, M.S.; KOETZ, P.R. Avaliação de um sistema combinado de UASB-Filtro no tratamento anaeróbio de águas residuárias de suinocultura. Olam Ciência \& Tecnologia, Rio Claro, v.2, n.2, 2002.

SANCHEZ, E.; MILAN, Z.; WEILAND, P.; RODRIGUEZ, Z.X. Piggery waste treatment by anaerobic digestion and nutrient removal by ionic exchange. Resources Conservation and Recycling, Amsterdam, v.15, n.3-4, p.235-44, 1995.

SOUZA, C.F. Biodigestão anaeróbia de dejetos de suínos: obtenção de dados e aplicação no desenvolvimento de um modelo dinâmico de simulação da produção de biogás. 2001. 140 f. Tese (Doutorado em Produção Animal) - Faculdade de Ciências Agrárias e Veterinárias, Universidade Estadual Paulista, Jaboticabal, 2001.

VAZOLLER, R.F. Microbiologia e saneamento ambiental. Disponível em: $<$ http://www.bat.fat.org.br>. Acesso em: 4 fev. 2002. 